\title{
KARAKTERISTIK MARSHALL DAN STIFFNESS MODULUS PADA LAPIS TIPIS CAMPURAN ASPAL PANAS DENGAN PENAMBAHAN CRUMB RUBBER
}

\author{
"The Characteristic of Marshall and Stiffness Modulus on \\ Thin Surfacing Hot Mix Asphalt with Crumb Rubber" \\ Maulana Andhika Pratama Ilyas ${ }^{1)}$, Ary Setyawan ${ }^{2)}$, Djumari ${ }^{3)}$ \\ 1)Mahasiswa Program Studi Teknik Sipil, Universitas Sebelas Maret \\ 2) 3)Pengajar Program Studi Teknik Sipil, Universitas Sebelas Maret \\ Jln Ir Sutami 36 A, Surakarta 57126 \\ e-mail : maulanaandhikapi@gmail.com
}

\begin{abstract}
The use of Thin Surfacing Hot Mix Asphalt is one alternative that can anticipate the problem of thickness of pavement. Crumb rubber (CR) is a result of tire retreading which is a serious problem for the environment and the use of crumb rubber is cheaper than natural rubber or other types of polymer. The purpose of this study was to assess the optimum asphalt content on the Thin Surfacing Hot Mix Asphalt with the addition of crumb rubber and without the addition of crumb rubber and compare the effect of adding crumb rubber to the stiffness modulus characteristics in each mixture. With the experimental method using the Marshall method, the stability value can be determined to determine the optimum bitumen content of each mixture that will be carried out at the Sebelas Maret University Road Pavement Laboratory. Furthermore, the Indirect Tensile Stiffness Modulus method can be used to determine the magnitude of the stiffness modulus to be carried out at the Pusjatan Road Pavement Laboratory of the Ministry of Public Works and Public Housing in Bandung as well as at the Udayana University Road Pavement Laboratory. The asphalt used is asphalt penetration 60/70 with the addition of crumb rubber of $0 \%, 0.5 \%, 1.0 \%$ and $1.5 \%$ of the total mixture weight. From the results of the marshall test, optimum asphalt levels were obtained for each level of crumb rubber $0 \%, 0.5 \%, 1.0 \%$ and $1.5 \%$ is 5.41\%, 5.50\%, 5.39\% and 5.52\%. Thin Surfacing Hot Mix Asphalt with the addition of 1\% Crumb Rubber reduced the Optimum Asphalt Levels by $0.4 \%$ and increased the stability value by 2\% compared to the Thin Surfacing Hot Mix Asphalt without the addition of 1\% Crumb Rubber. While for the ITSM test of the Thin Surfacing Hot Mix Asphalt with the addition of 1\% Crumb Rubber, the Stiffness Modulus value decreases by $51.3 \%$ to $20^{\circ} \mathrm{C}$, and increases the Stiffness Modulus by $30.7 \%$ to $40^{\circ} \mathrm{C}$. In addition, Thin Surfacing Hot Mix Asphalt with the addition of 1\% Crumb Rubber has a greater resistance to temperature, namely only $75 \%$ decrease in the value of stiffness modulus from a temperature of $20^{\circ} \mathrm{C}$ to a temperature of $40^{\circ} \mathrm{C}$ compared to Thin Surfacing Hot Mix Asphalt without the addition of Crumb Rubber $1 \%$ that is equal to 91\%.
\end{abstract}

Keywords: Crumb rubber, marshall properties, stiffness modulus, thin surfacing hot mix asphalt.

\begin{abstract}
Abstrak
Penggunaan lapis tipis campuran aspal panas (Thin Surfacing Hot Mix Asphalt) merupakan salah satu alternatif yang dapat mengantisipasi masalah ketebalan perkerasan jalan. Crumb rubber (CR) merupakan limbah hasil dari vulkanisir ban yang merupakan masalah serius bagi lingkungan dan penggunaan crumb rubber lebih murah daripada karet alam atau jenis-jenis polymer yang lain. Tujuan dari penelitian ini adalah untuk mengkaji kadar aspal optimum pada Thin Surfacing Hot Mix Asphalt dengan penambahan crumb rubber dan tanpa penambahan crumb rubber serta membandingkan pengaruh penambahan crumb rubber terhadap karakteristik stiffness modulus pada masing masing campuran. Dengan metode eksperimental menggunakan metode Marshall dapat ditentukan nilai stabilitas untuk mengetahui kadar aspal optimum masing masing campuran yang akan dilaksanakan di Laboratorium Jalan Raya Universitas Sebelas Maret Surakarta. Selanjutnya, metode Indirect Tensile Stiffness Modulus dapat digunakan untuk menentukan besarnya stiffness modulus akan dilaksanakan di Laboratorium Perkerasan Jalan Pusjatan Kementerian Pekerjaan Umum dan Perumahan Rakyat di Bandung serta di Laboratorium Jalan Raya Universitas Udayana Bali. Aspal yang digunakan adalah aspal penetrasi 60/70 dengan penambahan crumb rubber sebesar 0\%, 0,5\%, 1,0\% dan 1,5\% dari berat total campuran. Dari hasil marshall test diperoleh kadar aspal optimum yaitu untuk masing-masing kadar crumb rubber $0 \%$, 0,5\%, 1,0\% dan 1,5\% yaitu 5,41\%, 5,50\%, 5,39\% dan 5,52\%. Thin Surfacing Hot Mix Asphalt dengan penambahan Crumb Rubber 1\% menurunkan nilai Kadar Aspal Optimum sebesar 0,4\% dan meningkatkan nilai stabilitas sebesar 2\% dibandingkan dengan Thin Surfacing Hot Mix Asphalt tanpa penambahan Crumb Rubber 1\%. Sedangkan untuk uji ITSM dari Thin Surfacing Hot Mix Asphalt dengan penambahan Crumb Rubber 1\% menurunkan nilai Stiffness Modulus sebesar 51,3\% untuk suhu $20^{\circ} \mathrm{C}$, dan meningkatkan nilai Stiffness Modulus sebesar 30,7\% untuk suhu $40^{\circ} \mathrm{C}$. Selain itu, Thin Surfacing Hot Mix Asphalt dengan penambahan Crumb Rubber 1\% mempunyai ketahanan terhadap suhu lebih besar yaitu hanya 75\% penurunan nilai stiffness modulus dari suhu $20^{\circ} \mathrm{C}$ ke suhu $40^{\circ} \mathrm{C}$ dibandingkan dengan Thin Surfacing Hot Mix Asphalt tanpa penambahan Crumb Rubber $1 \%$ yaitu sebesar $91 \%$.
\end{abstract}

Kata Kunci: Remah karet, karakteristik marshall, modulus kekakuan, lapis tipis campuran aspal panas. 


\section{PENDAHULUAN}

Jalan adalah infrastruktur kunci perekonomian suatu daerah. Banyak diantara semua jalan tersebut menggunakan flexible pavement atau perkerasan lentur yang menggunakan campuran aspal sebagai bahan utamanya. Namun aspal sangat rentan terhadap beban yang berlebih atau overload dan perubahan suhu yang ekstrem. Peningkatan kepadatan lalu lintas juga dapat ketahanan dan kinerja jalan sehingga berkurangnya umur masa layan suatu jalan.

Salah satu metode yang sering dipakai untuk memperbaiki kondisi jalan adalah dengan cara overlay (lapis ulang). Namun pelapisan baru struktur perkerasan dengan tingkat ketebalan cukup tebal serta dilakukan terus menerus akan membentuk ketebalan lapisan permukaan jalan yang semakin tinggi.

Penggunaan lapis tipis campuran aspal panas (Thin Surfacing Hot Mix Asphalt) merupakan salah satu alternatif yang dapat digunakan untuk mengantisipasi masalah ketebalan itu sendiri.

Thin Surfacing HMA merupakan lapis permukaan yang sangat tipis seperti permukaan dressing dan slurries, lapis permukaan tipis ini memiliki ketebalan dari $30 \mathrm{~mm}$ sampai $40 \mathrm{~mm}$ (Nicholls, 1998).

Gilbert et al, (2004) menyatakan bahwa tujuan utama pengunaan Lapis Tipis HMA (Thin Surfacing Hot Mix Asphalt) adalah untuk perawatan permukaan perkerasan jalan. Lapis tipis HMA dapat memperpanjang masa layan dan meningkatkan kinerja perkerasan seperti kelancaran, kenyamanan, kekesatan, mengurangi kebisingan.

Keunggulan dari Thin Asphalt Overlays yaitu umur masa layan yang panjang, permukaan yang halus, mampu menahan lalu lintas yang berat dan tegangan geser yang besar, skid resisten yang tinggi, dan mudah perawatannya (Newcomb, 2009).

Al-Abdul-Wahhab dan Al-Amri (1991), menyatakan bahwa penggunaan crumb rubber yang dicampur dengan bitumen memiliki daya tahan terhadap selip, dapat mengurangi retak dan umur lapisan perkerasan yang lebih baik daripada jenis lapisan bitumen konvesional. Mereka berdua meneliti tentang efek penggunaan crumb rubber sebagai modifikasi agregat di laboratorium. Crumb rubber yang digunakan memiliki kandungan sebesar 1-6\% dari berat agregat (Dry Prosses).

Penambahan bahan tambah seperti serbuk ban bekas ke dalam campuran aspal dapat memberikan daya tahan yang lebih baik terhadap suhu tinggi maupun beban, dibandingkan dengan aspal tanpa penambahan bahan tambah. Penambahan bahan tambah pada aspal dapat memberikan indikasi untuk memperbaiki ketahanan geser pada suhu tinggi sehingga mencegah terjadinya kerusakan. (Aprina dan Silfiani, 2005).

Limbah karet ini berbentuk ban luar bekas yang mudah dijumpai di tukang tambal ban di sekitar kita. Karet padat yang dipakai merupakan karet yang biasa dipakai sebagai ban luar bekas yang berbentuk potongan-potongan ban luar bekas. Limbah ban karet lapisan ini kemungkinan besar dapat dipergunakan sebagai bahan tambahan aspal panas, karena sifatnya sama seperti karet alam. Karena lapisan karet ini masih berbentuk padat. (Darunifah, 2007).

Febrianto (2014) meneliti dan mendapatkan hasil bahwa campuran lapis tipis HMA aspal penetrasi 60/70 dengan penambahan crumb rubber memberikan kinerja yang baik khususnya dalam mengatasi deformasi. Hal ini didasari dari nilai stabilitas mengalami kenaikan pada penambahan $C R 0,3 \%$ dan $0,5 \%$ yaitu $742,223 \mathrm{~kg}(C R 0 \%)$ menjadi 766,540 $\mathrm{kg}$ dan $750,458 \mathrm{~kg}$ (CR 0,3\% dan CR 0,5\%).

\section{GRADASI AGREGAT}

Agregat adalah partikel mineral yang berbentuk butiran-butiran yang merupakan salah satu penggunaan dalam kombinasi dengan berbagai macam tipe mulai dari sebagai bahan material di semen untuk membentuk beton, lapis pondasi jalan, material pengisi, dan lain-lain (Harold N. Atkins, PE. 1997).

Spesifikasi yang digunakan pada campuran Thin Surfacing Hot Mix Asphalt mengacu pada National Asphalt Pavement Association (NAPA). Gradasi yang digunakan pada campuran ini adalah gradasi envelop yang merupakan standar dari North Carolina. Maksimum ukuran agregat penyusun Thin Surfacing HMA ini adalah 12,5 $\mathrm{mm}$ atau tertahan oleh saringan nomor $1 / 2$.

Tabel 1. Perencanaan gradasi

\begin{tabular}{lllc}
\hline Ukuran Saringan $(\mathbf{m m})$ & Spesifikasi & Median & Gradasi Pilihan \\
\hline 3/4" $(19 \mathrm{~mm})$ & 100 & & 100 \\
\hline 1/2" $(12,5 \mathrm{~mm})$ & $85-100$ & 92,5 & 92,65 \\
\hline $3 / 8 "(9,5 \mathrm{~mm})$ & $60-80$ & 70 & 69,3 \\
\hline No.4 $(4,75 \mathrm{~mm})$ & $28-38$ & 33 & 33,62 \\
\hline No.8 $(2,36 \mathrm{~mm})$ & $19-32$ & 25,5 & 25,16 \\
\hline No.50 $(0,30 \mathrm{~mm})$ & $8-13$ & 10 & 10,6 \\
\hline
\end{tabular}




\begin{tabular}{llll}
\hline No.200 $(0,075 \mathrm{~mm})$ & $4-7$ & 5,5 & 5,68 \\
\hline
\end{tabular}

Tabel 1 menunjukan perencanaan gradasi agregat yang akan digunakan untuk mencari kadar aspal optimum serta Stiffness Modulus.

Penelitian yang dilakukan sebelumnya oleh Nugroho Febrianto, 2014, tentang "Sifat-sifat Marshall pada Lapis Tipis Campuran Aspal Panas dengan Penambahan Crumb Rubber" dengan menggunakan gradasi dan agregat yang sama diperoleh pada gradasi pada nilai tengah menunjukkan nilai stabilitas yang tertinggi pada metode marshall.

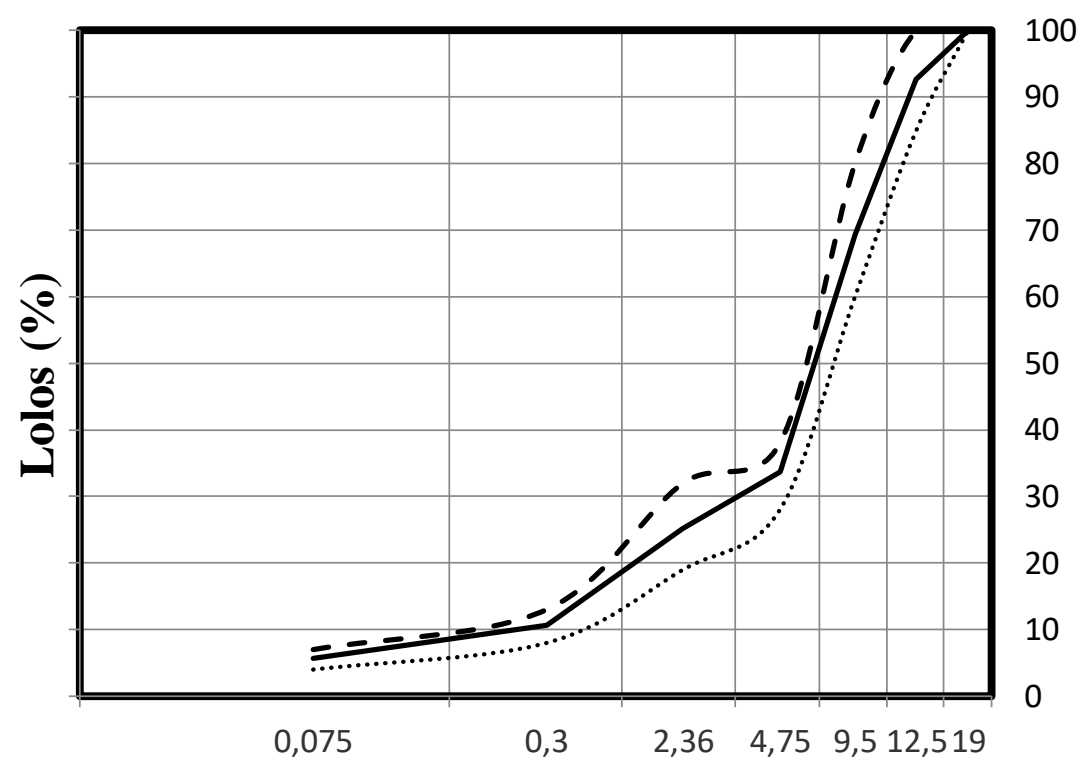

Nomor Saringan

Gambar 1. Gradasi Agregat Pilihan Untuk Campuran Thin Surfacing

HMA National Asphalt Pavement Association, North Carolina.

Gambar 1 menunjukkan grafik Gradasi agregat untuk campuran lapis tipis aspal panas, sesuai dengan standard National Asphalt Pavement Association, North Carolina.

\section{PERSAMAAN}

Berdasarkan Pedoman Teknik No.028 / T / BM / 1999, kadar aspal optimum rencana (Pb) diperoleh persamaan sebagai berikut ini:

$$
\mathrm{P}=0,035(\% \mathrm{CA})+0,045(\% \mathrm{FA})+0,18(\% \text { filler })+\mathrm{K}
$$

Dengan:

$\mathrm{P} \quad=$ Kadar aspal tengah/ideal, persen terhadap berat campuran.

CA $=$ Persen agregat tertahan saringan no.8.

FA $\quad=$ Persen agregat lolos saringan no. 8 dan tertahan saringan no.200.

Filler $\quad=$ Persen agregat minimal 75\% lolos saringan no. 200 .

$\mathrm{K}=$ Konstanta (0,5 - 1 untuk laston; $2-3$ untuk lataston; $1-2,5$ untuk campuran lain).

$$
D=\frac{\mathrm{W} d r y}{V}
$$

Dengan:

$$
\begin{array}{ll}
\mathrm{D} & =\text { Densitas } \\
\mathrm{W} d r y & =\text { Berat benda uji di udara } \\
\mathrm{V} & =\text { Volume }\left[\mathrm{V}_{\text {jenuh }}-\mathrm{V}_{\text {dalam air }}\right]
\end{array}
$$

$$
S G \operatorname{mix}=\left(\frac{100}{\frac{\% W c a}{S G c a}+\frac{\% W f a}{S G f a}+\frac{\% W f}{S G f}+\frac{\% W c r}{S G c r}+\frac{\% W b}{S G b}}\right)
$$

Dengan: 
SGmix = Specific gravity campuran

Wca = Prosentase berat agregat CA dalam campuran

$\mathrm{Wfa}=$ Prosentase berat agregat FA dalam campuran

$\mathrm{Wf} \quad=$ Prosentase berat agregat $\mathrm{F}$ dalam campuran

Wcr = Prosentase berat Crumb Rubber dalam campuran

$\mathrm{Wb}=$ Prosentase berat Bitumen dalam campuran

$\mathrm{SG} c a=$ Specific gravity agregat $\mathrm{CA}$

$\mathrm{SG} f a=$ Specific gravity agregat $\mathrm{FA}$

$\mathrm{SG} f=$ Specific gravity agregat $\mathrm{F}$

$\mathrm{SG}$ or $=$ Specific gravity agregat Crumb Rubber

$\mathrm{SG} b=$ Specific gravity agregat Bitumen

$P=1-\frac{\mathrm{D}}{\mathrm{SG} \operatorname{mix}}$

Dengan

$\mathrm{P} \quad=$ Porositas

$\mathrm{D} \quad=$ Densitas

SGmix = Spesific gravity campuran

$$
\mathrm{S}=\mathrm{q} \cdot \mathrm{k} \cdot \mathrm{H} \cdot 0,4536
$$

Dengan :

$\begin{array}{ll}\mathrm{S} & =\text { Stabilitas } \\ \mathrm{q} & =\text { Angka yang didapatkan dari dial stabiltas uji marshall } \\ \mathrm{k} & =\text { Angka kalibrasi cincin marshall } \\ \mathrm{H} & =\text { Tebal koreksi benda uji }\end{array}$

$$
\mathrm{MQ}=\frac{\mathrm{s}}{\mathrm{f}}
$$

Dengan :

$\begin{array}{ll}\mathrm{MQ} & =\text { Marshall Quotient } \\ \mathrm{S} & =\text { Stabilitas } \\ \mathrm{f} & =\text { Flow }\end{array}$

\section{KADAR ASPAL OPTIMUM DENGAN UJI MARSHALL}

Kadar aspal optimum dapat ditentukan dengan melakukan uji Marshall atau yang sering disebut dengan metode Asphalt Institute. Pengujian Marshall dilakukan berdasarkan perkiraan kadar aspal sementara dengan variasi kadar aspal $4,5 \%, 5 \%, 5,5 \%, 6 \%, 6,5 \%$ dan variasi kadar crumb rubber $0 \%, 0,5 \%, 1,0 \%$ dan 1,5\%. Sebelum uji Marshall dilakukan, terlebih dahulu dilakukan uji Volumetrik meliputi pengukuran diameter, tebal dan berat di udara, kemudian dilakukan perhitungan untuk mendapatkan nilai densitas, SGmix, dan porositas. Kemudian baru dilakukan pengujian Marshall dan didapatkan nilai stabilitas, flow, dan Marshall Quotient. Dari nilai - nilai tersebut dapat ditentukan sifat campuran yang terbaik atau kadar aspal optimum yang kemudian dijadikan sebagai dasar dalam pembuatan benda uji berikutnya.

Dari hasil pengujian Marshall didapatkan parameter-parameter berupa nilai flow, stabilitas dan Marsabll Quotient, dari data tersebut akan didapatkan nilai kadar aspal optimum dari aspal yang digunakan.

Tabel 2.Hasil Pengujian Marshall.

\begin{tabular}{ccccccc}
\hline $\begin{array}{c}\text { Kadar } \\
\text { Aspal } \\
(\%)\end{array}$ & $\begin{array}{c}\text { Stabilitas } \\
(\mathrm{kg})\end{array}$ & Pori $(\%)$ & $\begin{array}{c}\text { Flow } \\
(\mathrm{mm})\end{array}$ & $\begin{array}{c}\text { Bulk } \\
\text { Density } \\
(\mathrm{gr} / \mathrm{cm})\end{array}$ & $\begin{array}{c}\text { Marshall } \\
\text { Quotient } \\
(\mathrm{kg} / \mathrm{mm})\end{array}$ & $\begin{array}{c}\text { Kadar } \\
\text { CR } \\
(\%)\end{array}$ \\
\hline 4.5 & 670,692 & 5,063 & 2,633 & 2,23 & 300,14 & 1,5 \\
\hline 5.0 & 696,810 & 3,437 & 2,533 & 2,35 & 310,53 & 1,5 \\
\hline 5.5 & 826,851 & 3,353 & 2,433 & 2,24 & 317,72 & 1,5 \\
\hline 6.0 & 774,450 & 3,133 & 2,400 & 2,23 & 254,72 & 1,5 \\
\hline 6.5 & 648,750 & 3,219 & 2,167 & 2,21 & 274,67 & 1,5 \\
\hline 4.5 & 755,676 & 6,196 & 2,530 & 2,21 & 309,98 & 1,0 \\
\hline
\end{tabular}




\begin{tabular}{ccccccc}
\hline 5.0 & 913,460 & 5,205 & 2,500 & 2,22 & 376,91 & 1,0 \\
\hline 5.5 & 939,361 & 4,393 & 2,500 & 2,23 & 417,07 & 1,0 \\
\hline 6.0 & 771,088 & 3,352 & 2,900 & 2,24 & 266,54 & 1,0 \\
\hline 6.5 & 733,590 & 3,344 & 2,933 & 2,22 & 255,27 & 1,0 \\
\hline 4.5 & 713,059 & 5,884 & 2,400 & 2,24 & 300,14 & 0,5 \\
\hline 5.0 & 788,838 & 4,288 & 2,667 & 2,26 & 310,53 & 0,5 \\
\hline 5.5 & 877,449 & 3,928 & 2,767 & 2,25 & 317,72 & 0,5 \\
\hline 6.0 & 774,028 & 3,517 & 3,100 & 2,25 & 254,72 & 0,5 \\
\hline 6.5 & 722,299 & 2,995 & 2,833 & 2,24 & 274,67 & 0,5 \\
\hline 4.5 & 700,672 & 7,525 & 2,193 & 2,21 & 319,52 & 0 \\
\hline 5.0 & 896,402 & 5,603 & 2,367 & 2,24 & 385,33 & 0 \\
\hline 5.5 & 941,026 & 4,580 & 2,533 & 2,25 & 373,56 & 0 \\
\hline 6.0 & 714,000 & 4,666 & 2,500 & 2,23 & 291,51 & 0 \\
\hline 6.5 & 703,733 & 3,596 & 2,533 & 2,24 & 288,55 & 0 \\
\hline
\end{tabular}

Tabel 2 menunjukkan hasil pengujian Marshall, didapatkan nilai Stabilitas, Flow, Marshall Quotient. Data ini akan diolah sehingga diperoleh kadar aspal optimum campuran.

\section{STABILITAS}

Dari hasil tabel di atas, hubungan antara kadar aspal dengan stabilitas dituangkan dalam gambar 2 sebagai berikut:

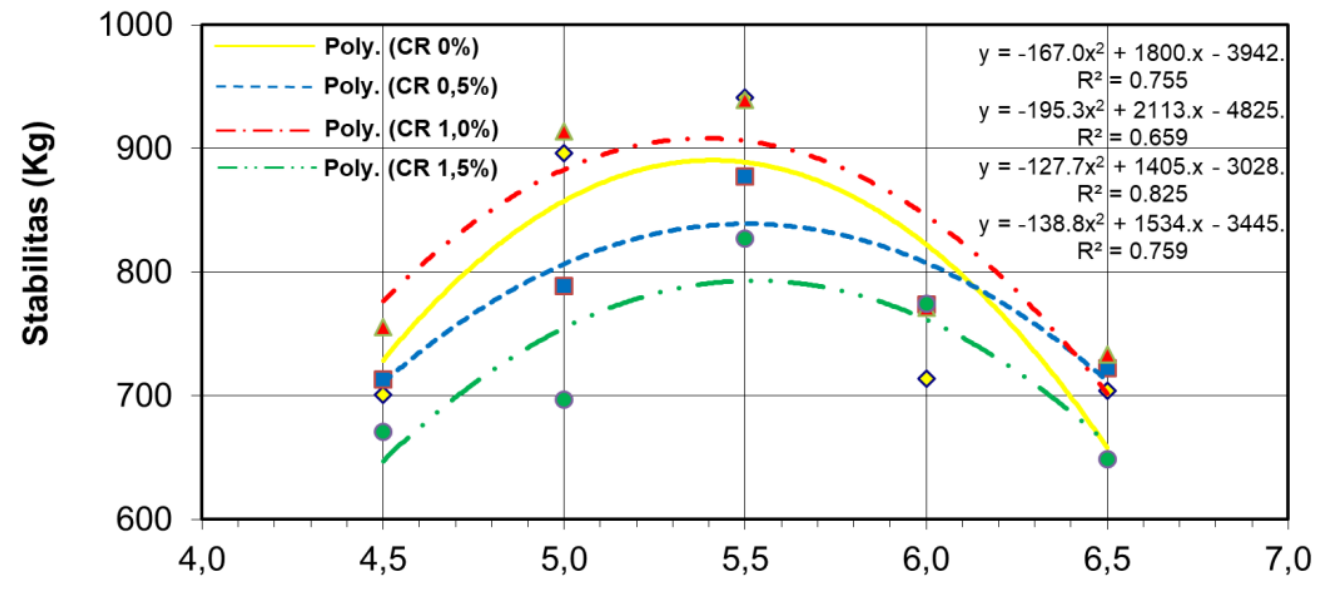

Kadar Aspal (\%)

Gambar 2. Grafik Hubungan Kadar aspal dengan Stabilitas

Dari gambar 2 grafik diperoleh garis persamaan tiap-tiap aspal yaitu

Aspal tanpa penambahan crumb rubber:

$y=-195,3 x 2+2113 x-4825$

Dengan :

$\mathrm{R}^{2}=0,659$

Ymax $=890,3$

$\mathrm{X} \max =5,41$

Aspal dengan penambahan crumb rubber $0,5 \%$ :

$y=-127,7 x 2+1405 x-3028$

Dengan :

$\mathrm{R}^{2}=0,825$

$\mathrm{Ymax}=836,575$

$\mathrm{X} \quad=5,50$

Aspal dengan penambahan crumb rubber 1,0\%:

$y=-167,0 x 2+1800 x-3942$ 


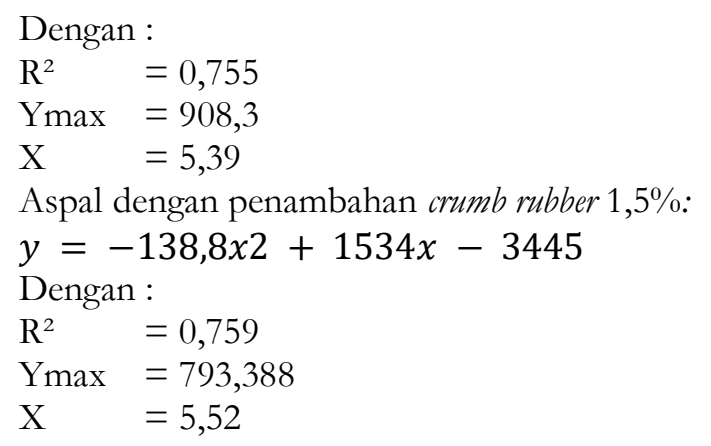

Dari aspal tanpa penambahan CR didapatkan kadar aspal optimum sebesar 5,41\% dengan nilai stabilitas sebesar 941,026kg, sedangkan untuk aspal dengan penambahan CR 1\% didapatkan kadar aspal optimum sebesar 5,39\% dengan nilai stabilitas $939,361 \mathrm{~kg}$.

\section{STIFFNESS MODULUS}

Stiffness Modulus didapat dari hasil pengujian Indirect Tensile Stiffness Modulus dilakukan untuk menghitung kemampuan ketahanan penyebaran pembebanan dari suatu campuran pada perkerasan dan kembali ke bentuk semula. Setelah pembuatan benda uji dengan Kadar Aspal Optimum (KAO), pengujian masing-masing tiga benda uji yang diuji pada suhu $20^{\circ} \mathrm{C}$ dan $40^{\circ} \mathrm{C}$.

Hasil pengujian ditampilkan dalam Gambar 3 menunjukkan bahwa Aspal dengan penambahan $C R$ lebih tahan terhadap perubahan suhu.

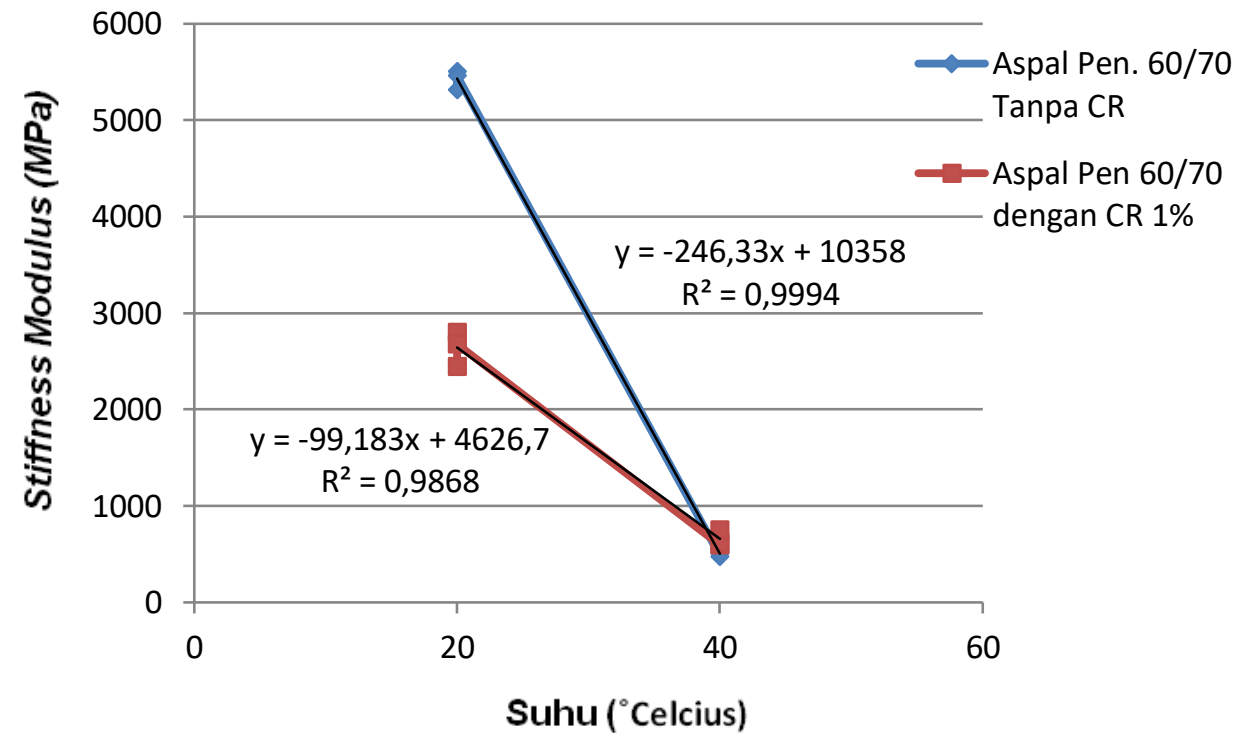

Gambar 3. Grafik Perbandingan Hasil Pengujian Indirect Tensile Stiffness Modulus pada Campuran Aspal

Dari gambar 3 dapat di simpulkan bahwa penurunan nilai stiffness modulus terhadap suhu pada aspal dengan penambahan crumb rubber lebih stabil dibanding dengan aspal tanpa penambahan crumb rubber hal ini terjadi karena penambahan crumb rubber dapat memberikan daya tahan yang lebih baik terhadap suhu yang lebih tinggi.

\section{SIMPULAN}

1). Dari hasil analisa grafik diperoleh kadar aspal optimum yaitu untuk masing-masing kadar crumb rubber $0 \%, 0,5 \%$, $1,0 \%$ dan $1,5 \%$ yaitu $5,41 \%, 5,50 \%, 5,39 \%$ dan 5,52\%. Thin surfacing hot mix asphalt dengan penambahan crumb rubber 1\% menurunkan nilai Kadar Aspal Optimum sebesar 0,4\% dan meningkatkan nilai stabilitas sebesar 2\% dibandingkan dengan thin surfacing hot mix asphalt tanpa penambahan crumb rubber $1 \%$.

2). Thin surfacing hot mix asphalt dengan penambahan crumb rubber $1 \%$ menurunkan nilai stiffness modulus sebesar $51,3 \%$ untuk suhu $20^{\circ} \mathrm{C}$, dan meningkatkan nilai stiffness modulus sebesar $30,7 \%$ untuk suhu $40^{\circ} \mathrm{C}$. Selain itu, thin surfacing hot mix asphalt dengan penambahan crumb rubber 1\% mempunyai ketahanan terhadap suhu lebih besar yaitu hanya $75 \%$ penurunan nilai stiffness modulus dari suhu $20^{\circ} \mathrm{C}$ ke suhu $40^{\circ} \mathrm{C}$ dibandingkan dengan thin surfacing hot mix asphalt tanpa penambahan crumb rubber $1 \%$ yaitu sebesar $91 \%$. 


\section{REFRENSI}

Al-Abdul-Wahab, H, and Al-Amri, G. 1991. Laboratory Evaluation of Reclaimed Rubber Asphaltic Concrete Mixes. King Fahd. Univ of Petroleum and Minerals. Saudi Arabia.

Aprina, Wiwin dan Silfiani. 2005. Karakteristik. Marshall dan Evaluasi Kadar Aspal Optimum Campuran Hot Rolled Sheet dengan Serbuk Ban Bekas Sebagai Bahan Tambah. Program Studi Teknik ITB. Bandung

Darunifah, N. 2007, Influence of Research Mixtures HRS-WC with The Addition of Solid Rubber Against Marshall Test. Master Thesis, Program Pasca Sarjana Universitas Diponegoro. Semarang.

Febrianto, Nugroho. 2014. Sifat-sifat Marshall pada Lapis Tipis Campuran Aspal Panas dengan Penambahan Crumb Rubber. Skripsi, Jurusan Teknik Sipil, Fakultas Teknik, Universitas Sebelas Maret. Surakarta.

Gilbert, T.M., Olivier, P. A., and Gale, N. E. 2004. Ultra Thin Friction Course: Five Years on in South Africa. Conference on Asphalt Pavements for Southern Africa. Afrika Selatan.

Harold N. Atkins. 1997. Highway Materials, Soils and Concretes, 3th Edition Prentice Hall, New Jersey.

Newcomb, D. E., and Hansen, K. R. 2006. Mix Type Selection for Perpetual Pavements. International Conference on Perpetual Pavements. Columbus, Ohio.

Nicholls, J. C., Carswell, I., and Williams, J. T. 2002. Durability of Thin Asphalt Surfacing Systems: Part 1 Initial Findings. United Kingdom. 